\title{
Remediation of copper ions from aqueous solution using hybrid magadiite: kinetics, isotherm and mechanism of removal
}

\author{
Malika Boudahri ${ }^{1} \cdot$ Djamila Bouazza $^{1} \cdot$ Mehdi Adjdir $^{2,3}$. \\ Hafida Miloudi $^{1} \cdot$ Nebatti Abdelkader $^{4} \cdot$ Abdelkader Tayeb $^{1}$
}

\begin{abstract}
This paper deals with the potential use of hybrid magadiite composite as an alternative adsorbent for the removal of copper ions. Na-magadiite was synthesized by the hydrothermal method. The hybrid magadiite was prepared by using pyrazolone as an organic ligand via dry impregnation technique from Na-magadiite. The hybrid magadiite composite is used in the removal of copper ions in sulphate media. The presence of an organic molecule in hybride magadiite is verified by thermogravimetric analysis and infrared spectroscopy. The X-ray diffraction pattern illustrates the intercalation of the organic ligand into Na-magadiite interlayers and the preservation of the structure after intercalation. The scanning electron micrograph images of modified Na-magadiite show the expansion of the basal spacing resulted in a breakup of the spherical nodules and the concomitant parallel arrangement of the platelets. In batch experiments, the influence of reaction time, kinetics, $\mathrm{pH}$ and the initial concentration of copper(II) were investigated. In the case of modified Na-magadiite, the kinetic model of extraction adapted is pseudo-second

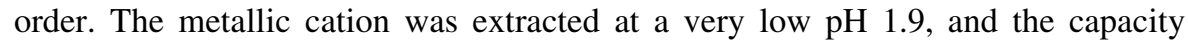
obtained is $330 \mathrm{mmol} / \mathrm{kg}$, the complex formed is of the $\mathrm{CuL}_{2}$ type.
\end{abstract}

Keywords Hydrothermal synthesis $\cdot$ Na-magadiite $\cdot$ Hybrid magadiite composite $\cdot$ Complex

Mehdi Adjdir

Mehdi.adjdir@daad alumni.de

1 Laboratoire de Chimie des Matériaux, Département de Chimie, Faculté des Sciences Exactes et Appliquées, Université d’Oran1 “Ahmed Ben Bella”, B.P. 1524, El Menaouer, 31000 Oran, Algeria

2 Division of Nanomineralogy, Institute of Functional Interfaces, Karlsruhe Institute of Technology, 76131 Karlsruhe, Germany

3 Department of Chemistry, Faculty of Sciences, University of Dr. Moulay Tahar, Sidon, Algeria

4 Institute of Science, University Centre Belhadj Bouchaib, Karlsruhe, Algeria 


\section{Introduction}

In the last few years there has been a growing interest in human activities such as mining, industry and sewage treatment discharges as well as electronic wastes, and agriculture fertilizers are some of the examples that contribute to the enhancement of heavy metal trace in wastewater such as Fe, Co, $\mathrm{Zn}$ etc., Among these heavy metals, copper is well known as one of the most harmful pollutants in the environment due to its high toxicity, non-degradability and bioaccumulation [1]. Recovery of these metals can be carried out by several methods such as adsorption, precipitation, electrodialysis, and liquid liquid extraction. Liquid solid extraction appeared as an alternative to liquid liquid extraction to prevent the use of hazardous organic solvents and for the regenerating of the solid adsorbent. This has prompted researchers to develop different solid adsorbents such as resins, zeolites, silicas and clays. So far, the use of these solids in the treatment of aqueous solutions is reported in the literature [2 6]. Most of these solid adsorbents present a lack of extraction capacity. To solve this problem, several researchers introduce different organic ligands into the solid matrix to increase their extraction capacities [7 10]. Guerra et al. [11] reported the use of natural and modified magadiite as adsorbents to remove Th(IV), U(VI), and Eu(III) from aqueous media in thermodynamic and equilibrium study. In most cases, the amount of heavy metal absorbed onto these organo-modified clays was much greater than that adsorbed onto the unmodified clays under the same experimental conditions $[12,13]$. The use of an organic ligand with natural clay may decrease the extraction capacity by causing an in situcomplexation with the metals that already exist in the natural clay. To avoid the mentioned phenomenon, synthetic clay as Na-magadiite has been used. The choice of this kind of synthetic clay is based on its physical and chemical properties similar to natural clay such as sorption of water and polar organic molecules [14], cation exchange of interlayer sodium cations $[15,16]$ and intercalation of different chemical species into the magadiite [17 22], toxic substance removal like arsenic(III) [23], and $\operatorname{arsenic}(\mathrm{V})$ [24]. It is known that the organic ligands are intercalated into H-magadiite. The aim of this study is to report the performance of the dry impregnation to intercalate 1-dodecanone,1-(5-hydroxy-3-methyl 1-p-tolyl$1 H$-pyrazol-4-yl) (HTMDDP) into Na-magadiite instead of $\mathrm{H}$-magadiite and its used in the copper(II) remediation process.

\section{Experimental}

\section{Reagents}

The silica gel (Ludox 40\%) and $\mathrm{NaOH}$ were obtained commercially from Aldrich. The 1-dodecanone, 1-(5-hydroxy-3-methyl 1-p-tolyl-1H-pyrazol-4-yl) (HTMDDP) (Fig. 1) was supplied by the SNPE Corp. France. The stock solutions of $\mathrm{Cu}$ (II) (1 g/ L) were prepared by dissolution of the corresponding salt $\left(\mathrm{CuSO}_{4}, \mathrm{Merck}\right.$ a.r. grade) 


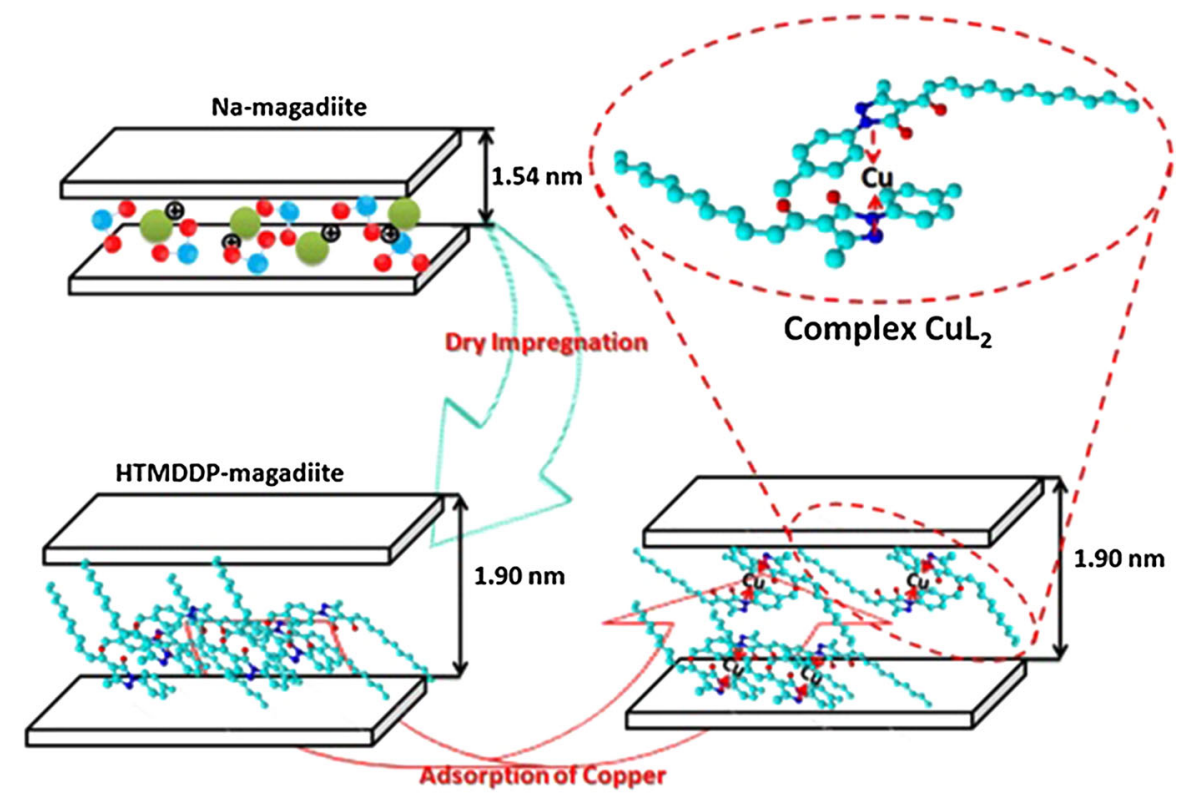

Fig. 1 Schematic diagram of the dry impregnation and adsorption process of copper

in deionized water. The reagents used for the preparation of different solutions such as $\mathrm{Na}_{2} \mathrm{SO}_{4}, \mathrm{H}_{2} \mathrm{SO}_{4}$ and toluene are all Merck a.r. grade.

\section{Synthesis of Na-magadiite}

Na-magadiite (Na-mag) was prepared by the reaction of a silica gel, sodium hydroxide and deionized water as described by Okutomo et al. [25] with a molar ratio $\mathrm{SiO}_{2}: \mathrm{NaOH}: \mathrm{H}_{2} \mathrm{O}=9: 3: 162$. After stirring for $2 \mathrm{~h}$ at room temperature, the mixture was transferred to a Teflon-lined cylindrical reactor, sealed and then heated at $150{ }^{\circ} \mathrm{C}$ for $48 \mathrm{~h}$. The dispersion was then filtered and remaining solids were washed carefully with distilled water and dried at $70{ }^{\circ} \mathrm{C}$ during $12 \mathrm{~h}$.

\section{Preparation of hybrid magadiite composite}

The HTMDDP (see Fig. 1) was introduced into the solid supports by using the dry impregnation method [23]. An appropriate amount of Na-mag is mixed with $10 \mathrm{~mL}$ of toluene solution containing $1 \mathrm{mmol}$ of HTMDDP. The mixture is continuously stirred up until total evaporation of the solvent under atmospheric pressure. The obtained solid was washed with $\mathrm{HNO}_{3} 0.5 \mathrm{M}$, to avoid the ligand dissolution in the aqueous phase in the form of its anion $\mathrm{A}^{-}$, then dried under atmospheric pressure at $80{ }^{\circ} \mathrm{C}$ for $24 \mathrm{~h}$. The impregnated material obtained is named Hybrid mag. 


\section{Methods and characterization}

In this study, various techniques were employed to characterize the Na-magadiite: the structures were analyzed by X-ray diffraction (XRD) using a Bruker-model D8 Advance $\mathrm{X}$-ray diffractometer working with $\mathrm{Cu}$ radiation $(\lambda=1.5406 \AA)$ and grazing incidence optics. The angle of incidence was $2^{\circ}$ in order to be sensitive to the near surface region. Attenuated total reflectance infrared spectra (4000 $400 \mathrm{~cm}^{-1}$ ) of the solids were recorded with an ATI Mattson genesis series Fourier transform infrared spectrometer (FTIR). The thermal stability was studied by means of thermal gravimetric analysis (TGA) and differential thermal analysis (DTA) (Mac Science 2000S instrument). The samples were heated in the temperature range of $251000{ }^{\circ} \mathrm{C}$ with $10{ }^{\circ} \mathrm{C} / \mathrm{min}$ heating rate under synthetic air atmosphere. To complete the study of the morphology features, some samples were analyzed by the scanning electron microscopy (SEM) (Model JEOL JSM-840). Finally, the mass of impregnated HTMDDP was quantitatively determined by UV visible spectrometry (Model HP 8453 Hewlett Packard) on the remaining washing solutions and mass-balance of the extractant.

\section{Metal extraction procedure}

The extraction of $\mathrm{Cu}(\mathrm{II})$ was carried out with batch experiments at $25{ }^{\circ} \mathrm{C}$. The $0.1 \mathrm{~g}$ of Na-mag and Hybrid-mag samples were mixed mechanically in polypropylene tubes with $10 \mathrm{~mL}$ of a $0.33 \mathrm{M}$ aqueous metal solution $\left(\mathrm{M}^{2+}, \mathrm{H}^{+}, \mathrm{Na}^{+}\right) \mathrm{SO}_{4}{ }^{2-}$ during $150 \mathrm{~min}$ separately. After phase separation with a high-speed centrifuge, the equilibrium $\mathrm{pH}\left(\mathrm{pH}_{\mathrm{e}}\right)$ was measured using a Jenco Electronics LTD pH-meter. Metal contents in aqueous phases were determined by atomic absorption spectroscopy on a Perkin Elmer 2380 spectrophotometer.

\section{Adsorption kinetic procedure}

The kinetic study was carried out as described in section "Methods and characterization" for contact times ranging from 0 to $400 \mathrm{~min}$. In order to understand the adsorption process, two kinetic models have been applied pseudofirst order and pseudo-second order.

\section{Results and discussion}

\section{Chemical analysis}

The chemical composition of the hybrid mag composite was found to be $660 \mathrm{mmol} /$ $\mathrm{kg}$. The impregnation yield is near $100 \%$. This result is in agreement with that found by Bouazza et al. [26]. 


\section{Infrared analysis}

The FT-IR spectra of Na-mag and Hybrid mag composite (Fig. 2) exhibited bands in the region between 1250 and $1090 \mathrm{~cm}^{-1}$ which could be assigned to antisymmetric stretching of the $\mathrm{Si} \mathrm{O} \mathrm{Si}$ bond in the tetrahedral configuration $v_{\mathrm{as}}$ (SiOSi) [14]. The band at $1630 \mathrm{~cm}^{-1}$ can be attributed to $\mathrm{H} \mathrm{O} \mathrm{H}$ bending vibration which shows the presence of some moisture in the samples. Bands in the $800600 \mathrm{~cm}^{-1}$ region will involve the corresponding symmetric vibrations. The absorption band at $465 \mathrm{~cm}^{-1}$ corresponds to bending vibration of Si O Si. All these features are typical of Na-magadiite structure [27]. The sharp band at $3650 \mathrm{~cm}^{-1}$ due to $\mathrm{OH}$ stretching vibration of isolated silanol groups bonded to the silicon in both Na-and hybrid magadiite interlayer. The broad band between 3656 and $3146 \mathrm{~cm}^{-1}$ is assigned to the hydroxyl stretching vibrations. In addition to the vibrations of the hydroxyl and silanol observed in the region between 3500 and $3200 \mathrm{~cm}^{-1}$, Hybrid mag exhibits additional bands that appeared at 2921 and $2837 \mathrm{~cm}^{-1}$ that could be assigned to the stretching vibration modes of antisymmetrical stretching $v_{\mathrm{as}(\mathrm{C}-\mathrm{H})}$ and symmetrical stretching $v_{\mathrm{s}(\mathrm{C}-\mathrm{H})}$, respectively, mainly attributed to vibration bands characteristic of HTMDDP [28]. These results confirm the presence of HTMDDP in X-ray diffraction. From the FTIR spectra, it can be concluded that the impregnation of HTMDDP into magadiite does not affect the functional groups that constituted the magadiite (FTIR) and no shift concerning these functional groups in comparison to Na-mag is observed. These can be related to the low amount of impregnated HTMDDP in Na-mag.

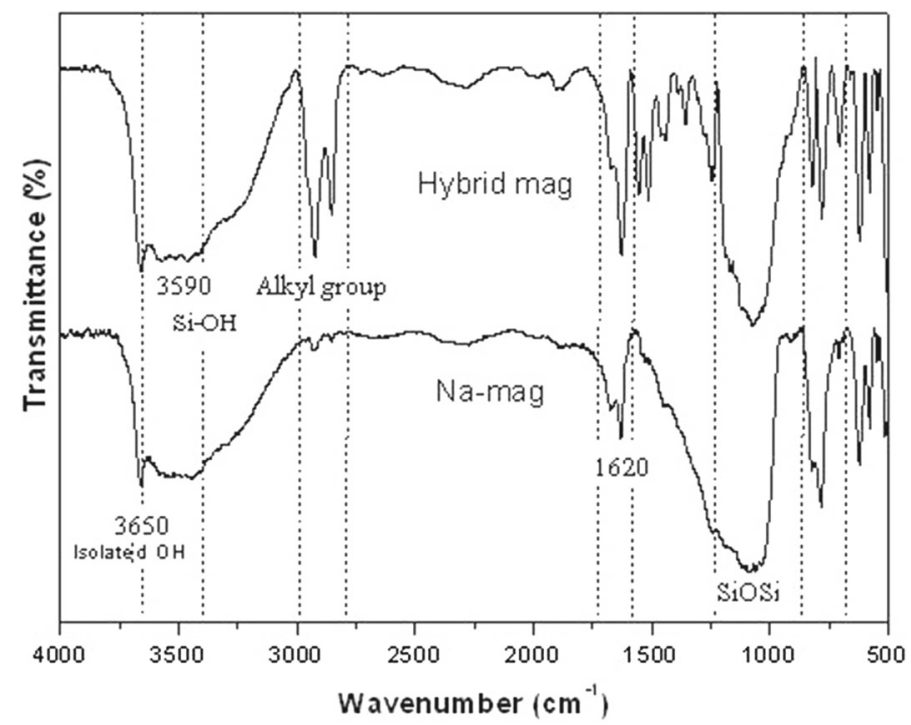

Fig. 2 Infrared transmission spectra of a Na mag, b Hybrid mag 


\section{X-ray diffraction}

The XRD patterns of Na-mag and Hybrid mag composite are illustrated in Fig. 3. The Na-mag showed a basal spacing of $d_{001}=1.54 \mathrm{~nm}$, reported for synthetic magadiite and exhibits all reflections that belong to a typical Na-magadiite [29, 30]. However, the hybrid mag sample exhibits typical basal space at $d_{001}=1.54 \mathrm{~nm}$ and an additional shoulder corresponding to $1.90 \mathrm{~nm}$. The intensity of the first reflection at $1.90 \mathrm{~nm}$ is very weak related to the loading concentrations of HTMDDP. This result is in good agreement with that found by Kooli et al. [29], when $\mathrm{C}_{16} \mathrm{TMABr}$ solution was used, partial intercalation occurred using a relatively low concentration of $0.42 \mathrm{~mol}$, with a small broad reflection at $3.10 \mathrm{~nm}$. The appearance of the peak corresponding to the basal spacing $1.90 \mathrm{~nm}$ probably indicates the onset of formation of meso-structure. The value of the basal spacing remains fixed at $d=1.54 \mathrm{~nm}$ which could coincide with that of the starting Na-magadiite and confirm the intercalation of HTMDDP in plan conformation in respect to the Jahn Teller effect [31]. These results confirm that the dry impregnation does not cause the appearance of contaminating phases or amorphization of the structure.

\section{DTG and DTA analysis}

Figure 4 gives an example of the thermogravimetric analysis of the samples. The DTG/DTA curves of Na-mag (a) exhibit three distinct stages of thermal degradation showing a $8.22 \%$ weight loss below $150{ }^{\circ} \mathrm{C}$ associated with the desorption of physically adsorbed water, second thermal stages were observed between 150 and $200{ }^{\circ} \mathrm{C}$ which presented a little mass loss $(0.38 \%)$, which is attributed to the

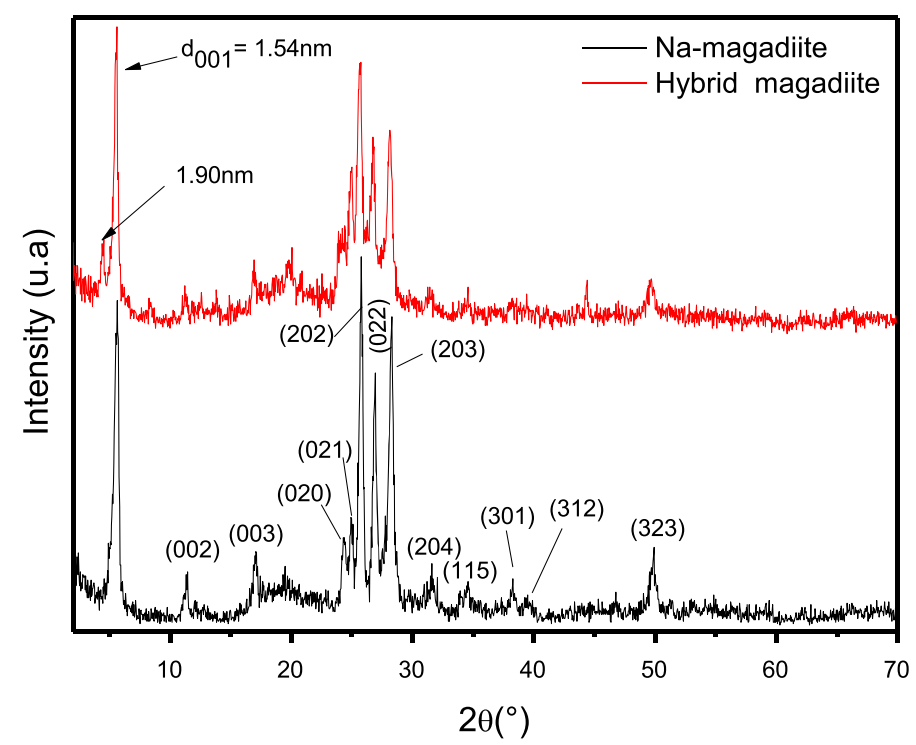

Fig. 3 Powder XRD patterns of a Na mag, b Hybrid mag 
(a)

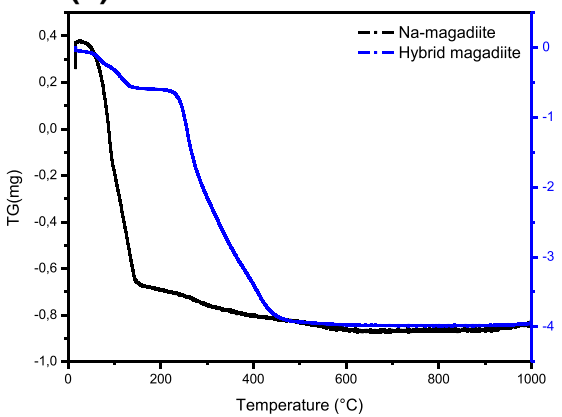

(b)

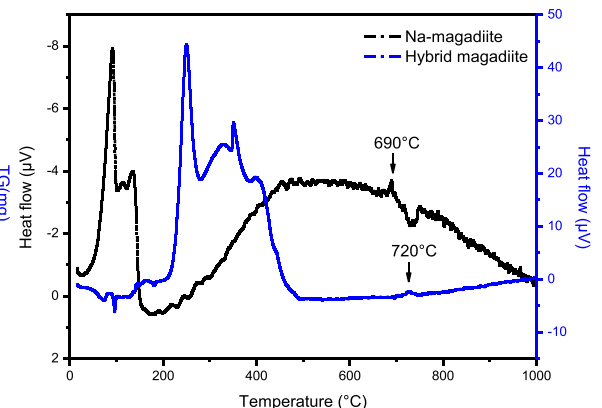

Fig. 4 TG (dashed line) and DTA (solid line) curves of a Na mag and b Hybrid mag

removal of water molecules intercalated and bound to $\mathrm{Na}^{+}$cations. The continuous weight loss of $1.76 \%$ attributed at an exothermic peak from $600{ }^{\circ} \mathrm{C}$ is attributed to the collapse of the structure and the reorganization into a new phase [30]. After dry impregnation of HTMDDP molecules (Fig. 4b), an important additional weight loss of $29.7 \%$ between 200 and $450{ }^{\circ} \mathrm{C}$ is observed, corresponding to the elimination of the organic ligand molecules.

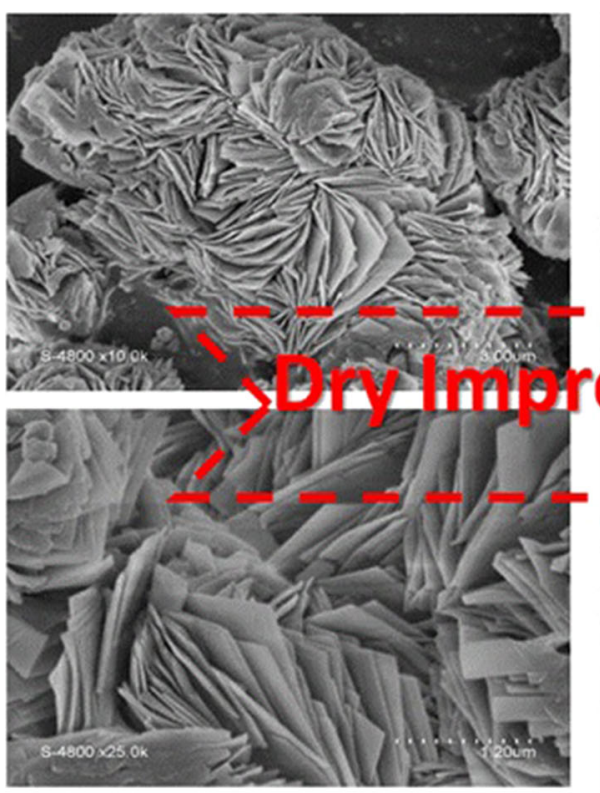

(a)

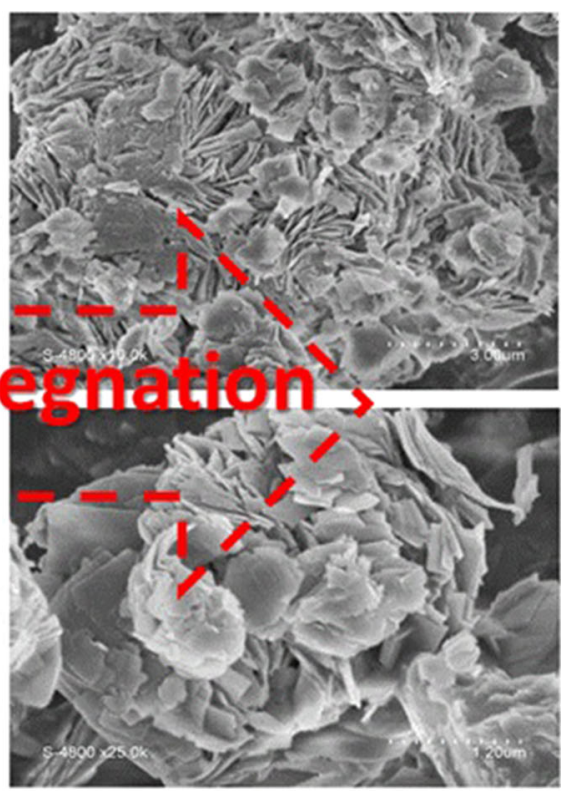

(b)

Fig. 5 Scanning electron micrograph of: a Na mag, b Hybrid mag 


\section{Morphology}

The scanning electron microscopy (SEM) images of Na-mag and Hybrid-mag composite are shown in Fig. 5. The Na-magadiite is composed of lamellae with some aggregates randomly distributed. This material presents microlayers resulting from intergrown particles, which form a rosette-like assembly, similar observation was mentioned in the literature [25] as nanometric petals. After intercalation with HTMDDP the rosette morphology was missing, it is seen that the expansion of the basal spacing resulted in a breakup of the spherical nodules and the concomitant parallel arrangement of the platelets. These observations support the result obtained by XRD analysis.

\section{Metal extraction}

The reaction equation for the complexation of divalent metals can be described as follows in liquid liquid extraction:

$$
\mathrm{M}^{2+}+2 \overline{\mathrm{HL}} \Leftrightarrow \overline{\mathrm{ML}}_{2}+2 \mathrm{H}^{+},
$$

(Reaction1)

where $\mathrm{M}$ represents the metal species and HL represents the HTMDDP ligand.

The ability of Hybrid mag composite to adsorb $\mathrm{Cu}$ (II) from aqueous solution was studied by varying different parameters such as agitation time, kinetics, $\mathrm{pH}$ and metal concentration.

The metal extraction percentage, $E \%$, can be expressed as follows:

$$
E \%=100 \times \frac{n_{M_{\mathrm{s}}}}{n_{M_{\mathrm{aq}, i}}},
$$

where $n_{M_{\mathrm{s}}}$ and $n_{M_{\mathrm{aq}, i}}$ denote the total number of moles of metal in the solid phase at equilibrium and the initial total number of moles of metal in the aqueous phase, respectively, and it is determined from the analytical concentrations of the metal in the aqueous phase before and after extraction $\left(\left[M_{\mathrm{aq}, i}\right]\right.$ and $\left.\left[M_{\mathrm{aq}, e}\right]\right)$ respectively:

$$
E \%=100 \times \frac{\left[M_{\mathrm{aq}, i}\right]-\left[M_{\mathrm{aq}, e}\right]}{\left[M_{\mathrm{aq}, i}\right]} .
$$

\section{Effect of shaking time and kinetics of adsorption}

The effect of the shaking contact time was studied using an initial $\mathrm{pH}\left(\mathrm{pH}_{i}\right)$ fixed at 2.56 for HTMDDP impregnated solid, Fig. 6 shows the evolution of extraction yields versus shaking time. The extraction increased with the $\mathrm{pH}$ and reaches a plateau after $150 \mathrm{~min}$ of contact. So, $150 \mathrm{~min}$ for the contact time was adopted for subsequent studies.

The pseudo-first order expressed in Eqs. $(3,4)$ and the pseudo-second order expressed in Eqs. $(5,6)$ were adopted to determine the kinetic order of the extraction process. 


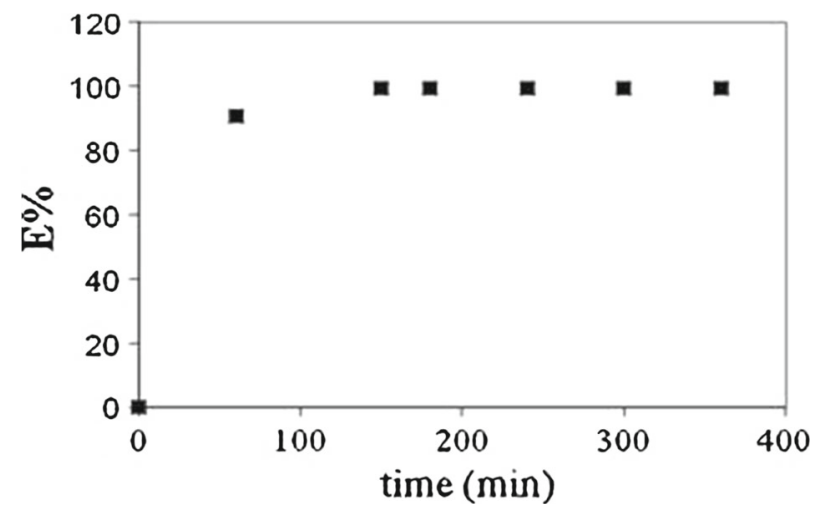

Fig. 6 Evolution of extraction pHi 2.56; $\left[\mathrm{Na}^{+}, \mathrm{H}^{+} \mathrm{SO}_{4}{ }^{2}\right] \quad 0.33 \mathrm{M} ; \quad T \quad 25{ }^{\circ} \mathrm{C} ; m \quad 0.1 \mathrm{~g}$; [HTMDDP] $\quad 0.66 \mathrm{mmol} / \mathrm{g}$

For a pseudo-first order reaction, the rate law is describe by the following equation

$$
\frac{\mathrm{d} q_{t}}{\mathrm{~d} t}=k_{1}\left(q_{e}-q_{t}\right)
$$

where $k_{1}$ the rate constant $\left(\min ^{-1}\right), q_{e}$ quantity of the metal ion extracted at equilibrium $(\mathrm{mmol} / \mathrm{g}), q_{t}$ quantity of the metal ion extracted at time $t$.

Equation (3) is integrated between 0 and $t$ with respect of time and between 0 and $q_{t}$ with respect of quantity of the metal ion extracted. In this way we obtain Eq. (4):

$$
\operatorname{Ln}\left(q_{e}-q_{t}\right)=\operatorname{Ln} q_{e}-k_{1} \cdot t .
$$

For a pseudo-second order reaction, the rate law is expressed as:

$$
\frac{\mathrm{d} q_{t}}{\mathrm{~d} t}=k_{2}\left(q_{e}-q_{t}\right)^{2},
$$

where $k_{2}$ is the rate constant $(\mathrm{g} / \mathrm{mmol} \mathrm{min})$.

After integration, the following integrated law is obtained:

$$
\frac{1}{q_{e}-q_{t}}=\frac{1}{q_{e}}+k_{2} \cdot t
$$

and it can be rearranged as follows:

$$
\frac{t}{q_{t}}=\frac{1}{k_{2} \cdot q_{e}^{2}}+\frac{1}{q_{e}} t .
$$

The rate constants and correlation coefficients were obtained by plotting $\operatorname{Ln}\left(q_{e}-q_{t}\right)$ as a function of time $t$ for pseudo-first order and $t / q_{t}$ versus time for pseudo-second order. The results are summarized in Table 1 and are shown in Figs. 7 and 8. 
Table 1 Rate constants $k$ of pseudo first order and pseudo second order reactions and correlation coefficients $R$ of $\mathrm{Cu}(\mathrm{II})$ sorption by Hybrid mag composite

\begin{tabular}{lllll}
\hline System & $R_{1}^{2}$ & $k_{1}$ & $R_{2}^{2}$ & $k_{2}$ \\
\hline Cu Hybrid mag & 0.5416 & 0.025 & 0.9997 & 1.450 \\
\hline
\end{tabular}

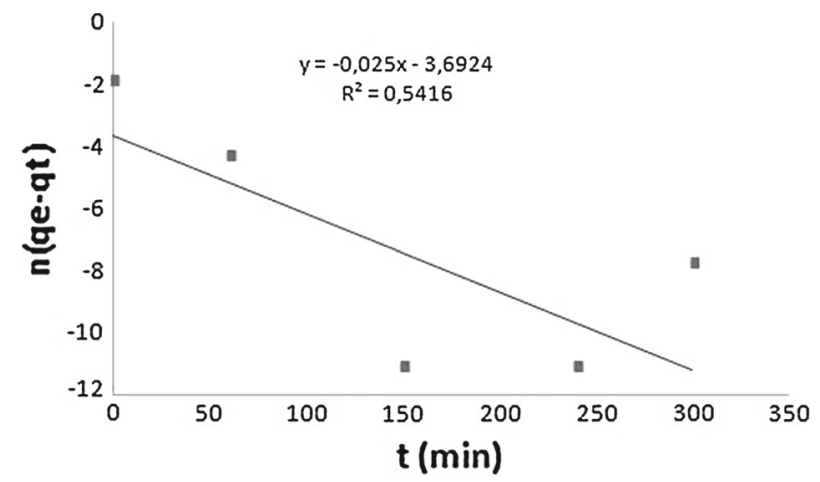

Fig. 7 Sorption kinetic pseudo first order for Hybrid mag

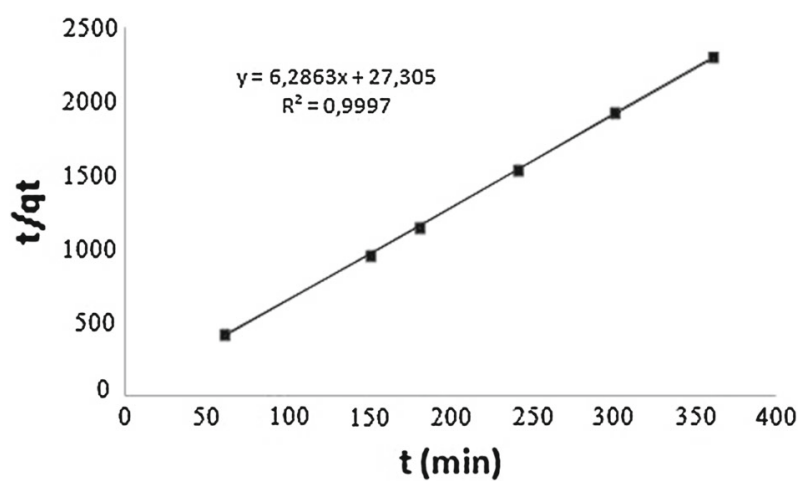

Fig. 8 Sorption kinetic pseudo second order for Hybrid mag

The correlation coefficients determined as well as the amounts of metal extracted at equilibrium was in good agreement with those determined experimentally.

According to the results given in Table 1 and shown in Figs. 7 and 8, the pseudosecond order model is best suited when the initial metal concentration is low. These results are in agreemlent with those found by Azizian [32, 33].

\section{Effect of equilibrium pH}

The metal extraction by Na-mag and Hybrid mag composite was studied as a function of the $\mathrm{pH}_{\mathrm{e}}$ (Fig. 9). The results showed that copper is extracted by Na-mag 


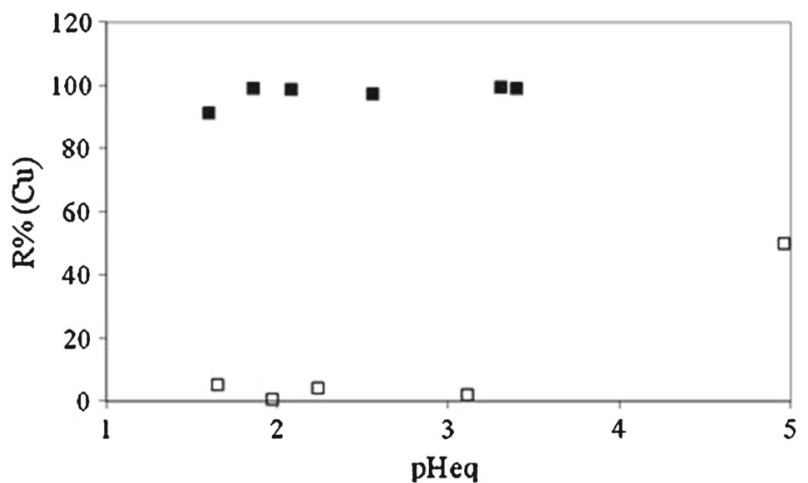

Fig. 9 Measured copper extraction percentages as functions of equilibrium $\mathrm{pH}\left(\mathrm{pH}_{\mathrm{e}}\right.$ ) (open square) $\mathrm{Na}$ mag, (filled square) Hybrid mag, $\left[\mathrm{Cu}^{2+}\right] 100 \mathrm{ppm} ; \quad\left[\mathrm{Na}^{+}, \mathrm{H}^{+} \mathrm{SO}_{4}^{2}\right] \quad 0.33 \mathrm{M} ; \quad T \quad 2{ }^{\circ} \mathrm{C}$; $T \quad 150 \mathrm{~min} ; m \quad 0.1 \mathrm{~g}$; [HTMDDP] $\quad 0,66 \mathrm{mmol} / \mathrm{g}$

at $\mathrm{pH} 5(50 \%)$. For Hybrid mag composite, the extraction took place at $\mathrm{pH}$ above 1. The extraction yield increases with the increases of $\mathrm{pH}_{\mathrm{e}}$ to reach its maximum $(100 \%)$ at $\mathrm{pH}_{\mathrm{e}} 1.9$. This can be explained by the interaction between the ligand and the Na-mag. The complexing sites are more accessible and are better oriented to bind to copper ions (Table 2).

\section{Extraction capacity}

Copper extraction capacity of the Hybrid mag composite was investigated at $\mathrm{pHi}$ 4.3. Initial $\mathrm{Cu}(\mathrm{II})$ concentration was adjusted in the range of $504000 \mathrm{mg} / \mathrm{L}$ $(0.7762 \mathrm{mmol} / \mathrm{L})$ and the adsorption curve is shown on Fig. 10. By the use of the composite solid, the adsorption efficiency increased even at a lower copper concentration $0.75 \mathrm{mmol} / \mathrm{L}(47.65 \mathrm{mg} / \mathrm{L})$. One plateau was observed with Hybrid mag composite.

The ligand $/$ metal ratio $L_{\mathrm{s}} / M_{\mathrm{s}}$ is estimated to 2 with a capacity of $330 \mathrm{mmol} / \mathrm{kg}$, where $L_{\mathrm{s}}$ is the total number of free or coordinated "TMDDP" sites and $M_{\mathrm{s}}$ is the total number of copper atoms in the solid. This ratio is obtained when the $\mathrm{CuL}_{2}$ complex type is formed. Thus, the extraction process is probably an ion exchange between $\mathrm{Cu}^{2+}$ in aqueous phase and $\mathrm{H}^{+}$protons of HTMDDP in solid phase. This phenomenon is also observed in liquid liquid extraction. This result is in agreement with those given by Miloudi et al. and Bou-Maroun et al. [34 36].

Table 2 Kinetic parameters of the pseudo second order Cu(II) sorption by Hybrid mag composite

\begin{tabular}{llllll}
\hline Systems & $C_{0}(\mathrm{mmol} / \mathrm{L})$ & $R_{2}^{2}$ & $k_{2}$ & $q_{\mathrm{e}, \mathrm{th}}(\mathrm{mmol} / \mathrm{g})^{\mathrm{a}}$ & $q_{\mathrm{e}, \text { exp }}(\mathrm{mmol} / \mathrm{g})^{\mathrm{b}}$ \\
\hline Cu Hybrid mag & 1.57 & 0.9997 & 1.450 & 0.159 & 0.157
\end{tabular}

${ }^{\mathrm{a}} q_{\mathrm{e}, \mathrm{th}}$ : quantity of the metal ion extracted at equilibrium and determined by Eq. 7

${ }^{\mathrm{b}} q_{\mathrm{e}, \text { exp }}$ : quantity of the metal ion extracted at equilibrium and experimentally determined 


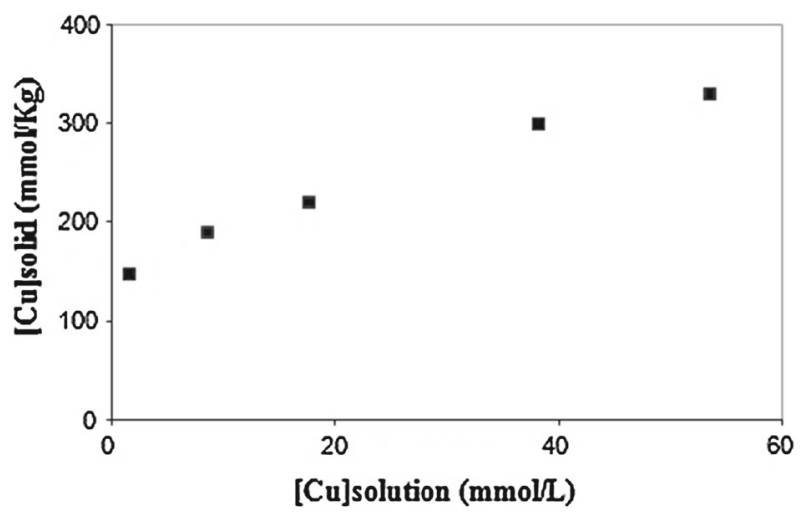

Fig. 10 Copper extraction capacity versus copper concentration at pHi 2.14; $\left[\mathrm{Na}^{+}, \mathrm{H}^{+}\right.$ $\mathrm{SO}_{4}{ }^{2}$ ] $\quad 0.33 \mathrm{M} ; T \quad 25^{\circ} \mathrm{C} ; T \quad 150 \mathrm{~min} ; m \quad 0.1 \mathrm{~g}$; [HTMDDP] $0.66 \mathrm{mmol} / \mathrm{g}$

\section{Conclusion}

From the outcome of our investigation it is possible to conclude that a simple and efficient synthesis route was carried out for the preparation of Na-magadiite. The Hybrid mag was successfully obtained by the dry impregnation method of Namagadiite and HTMDDP. On the basis of the XRD result, the Na-magadiite structure was conserved after impregnation. Concerning the FTIR, thermal and SEM measurement confirm the presence of the ligand in the Na-magadiidte structure. Moreover, the equilibrium time of copper extraction by Hybrid mag is obtained after $150 \mathrm{~min}$. The kinetic model of extraction adapted is pseudo-second order. Hybrid mag extracts copper at low pH 1.9, adapted to the treatment of acidic waste. The copper extraction capacity of the hybrid mag is $330 \mathrm{mmol} / \mathrm{kg}$, and the complex formed is confirmed to belong to $\mathrm{CuL}_{2}$ type. The extraction process is probably an ion exchange between $\mathrm{Cu}^{2+}$ in aqueous phase and $\mathrm{H}^{+}$protons of HTMDDP in solid phase.

Acknowledgements The authors are very grateful to Dr. Anne Boss (Institut Pluridisciplinaire Hubert Curien, UMR 7178, CNRS ECPM Université de Strasbourg, 25 rue Becquerel, 67087 Strasbourg Cedex, France) for her precious help.

\section{References}

1. T.S. Anirudhan, S. Rijith, Colloids Surf. A 351, 52 (2009)

2. J. Cortina, N. Miralles, A. Sastre, M. Aguilar, A. Profumo, M. Pesavento, React. Polym. 21, 89 (1993)

3. M. Pérez, I. Pavlovic, C. Barriga, J. Cornejo, M. Hermosin, M. Ulibarri, Appl. Clay Sci. 32, 245 (2006)

4. Y. Ide, N. Ochi, M. Ogawa, Angew. Chem. 123, 680 (2011)

5. N. Homhuan, S. Bureekaew, M. Ogawa, Langmuir 33, 9558 (2017)

6. W. Lim, J. H. Jang, N. Y. Park, S. M. Paek, W. C. Kim, M. Park, J. Mater. Chem. A 5, 4144 (2017)

7. T. Phothitontimongkol, N. Siebers, N. Sukpirom, F. Unob, Appl. Clay Sci. 43, 343 (2009) 
8. D. Bouazza, H. Miloudi, M. Sassi, A. Boos, G. Goetz, A. Tayeb, A. Bengueddach, J. Phys. Chem. Solids 67, 1032 (2006)

9. S. Z. Li, P. X. Wu, J. Hazard. Mater. 173, 62 (2010)

10. T. Sirinakorn, K. Imwiset, S. Bureekaew, M. Ogawa, Appl. Clay Sci. 153, 187 (2018)

11. D.L. Guerra, J.N. Ferrreira, M.J. Pereira, R.R. Viana, C. Airoldi, Clays Clay Miner. 58, 327 (2010)

12. M. Erdemoğlu, S. Erdemoğlu, F. Sayılkan, M. Akarsu, Ş. Şener, H. Sayılkan, Appl. Clay Sci. 27, 41 (2004)

13. A. de Mello Ferreira Guimarães, V.S.T. Ciminelli, W.L. Vasconcelos, Appl. Clay Sci. 42, 410 (2009)

14. I. Fujita, K. Kuroda, M. Ogawa, Chem. Mater. 15, 3134 (2003)

15. B. Royer, N.F. Cardoso, E.C. Lima, T.R. Macedo, C. Airoldi, J. Hazard. Mater. 181, 366 (2010)

16. K. Kikuta, K. Ohta, K. Takagi, Chem. Mater. 14, 3123 (2002)

17. K. Isoda, K. Kuroda, M. Ogawa, Chem. Mater. 12, 1702 (2000)

18. N. Miyamoto, R. Kawai, K. Kuroda, M. Ogawa, Appl. Clay Sci. 19, 39 (2001)

19. A. Mokhtar, A. Djelad, A. Boudia, M. Sassi, A. Bengueddach, J. Porous Mater. 24, 1627 (2017)

20. D.L. Guerra, A.A. Pinto, J.A. de Souza, C. Airoldi, R.R. Viana, J. Hazard. Mater. 166, 1550 (2009)

21. S. Benkhatou, A. Djelad, M. Sassi, M. Bouchekara, A. Bengueddach, Desalination Water Treat. 57, 9383 (2016)

22. A. Mokhtar, A. Djelad, A. Boudia, M. Sassi, A. Bengueddach, J. Porous Mater. 24, 1627 (2017)

23. D.L. Guerra, A.A. Pinto, C. Airoldi, R.R. Viana, J. Solid State Chem. 181, 3374 (2008)

24. D.L. Guerra, A.A. Pinto, R.R. Viana, C. Airoldi, Appl. Surf. Sci. 256, 702 (2009)

25. S. Okutomo, K. Kuroda, M. Ogawa, Appl. Clay Sci. 15, 253 (1999)

26. D. Bouazza, H. Miloudi, M. Adjdir, A. Tayeb, A. Boos, Appl. ClaySci. 151, 118 (2018)

27. Y. Guo, Y. Wang, Q. X. Yang, G. D. Li, C. S. Wang, Z. C. Cui, J. S. Chen, Solid State Sci. 6, 1001 (2004)

28. B.S. Jensen, Acta Chem. Scand. 13, 1668 (1959)

29. F. Kooli, L. Mianhui, S.F. Alshahateet, F. Chen, Z. Yinghuai, J. Phys. Chem. Solids 67, 926 (2006)

30. G. Lagaly, K. Beneke, Am. Miner. 60, 642 (1975)

31. R. Englman, R. Englman, The Jahn Teller Effect in Molecules and Crystals (Wiley, New York, 1972)

32. S. Azizian, J. Colloid Interface Sci. 276, 47 (2004)

33. S. Azizian, J. Colloid Interface Sci. 302, 76 (2006)

34. H. Miloudi, A. Boos, D. Bouazza, T. Ali Dahmane, A. Tayeb, G. Goetz Grandmont, A. Bengued dach, Mater. Res. Bull. 42, 769 (2007)

35. E. Bou Maroun, G.J. Goetz Grandmont, A. Boos, Colloids Surf. A 287, 1 (2006)

36. K. Torkestani, O. Blinova, J. Arichi, G. Goetz Grandmont, J. Brunette, Solv. Extr. Ion Exchange 14, 1037 (1996) 


\section{Repository KITopen}

Dies ist ein Postprint/begutachtetes Manuskript.

Empfohlene Zitierung:

Boudahri, M.; Bouazza, D.; Adjdir, M.; Miloudi, H.; Abdelkader, N.; Tayeb, A.

Remediation of copper ions from aqueous solution using hybrid magadiite: kinetics, isotherm and mechanism of removal.

2018. Research on chemical intermediates, 44

doi:10.5445/IR/1000089830

Zitierung der Originalveröffentlichung:

Boudahri, M.; Bouazza, D.; Adjdir, M.; Miloudi, H.; Abdelkader, N.; Tayeb, A.

Remediation of copper ions from aqueous solution using hybrid magadiite: kinetics, isotherm and mechanism of removal.

2018. Research on chemical intermediates, 44 (10), 6105-6117.

doi:10.1007/s11164-018-3478-x 